\title{
Study on Alternative Cargo Launch Options from the Lunar Surface
}

\section{Joint Propulsion Conference}

\author{
Cheryl A. Blomberg \\ Zamir A. Zulkefli \\ Spencer W. Rich \\ Steven D. Howe
}

The INL is a

U.S. Department of Energy

National Laboratory

operated by

Battelle Energy Alliance

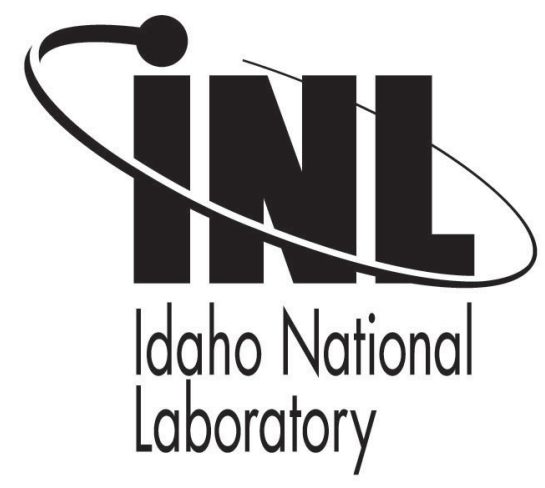

July 2013

This is a preprint of a paper intended for publication in a journal or proceedings. Since changes may be made before publication, this preprint should not be cited or reproduced without permission of the author. This document was prepared as an account of work sponsored by an agency of the United States Government. Neither the United States Government nor any agency thereof, or any of their employees, makes any warranty, expressed or implied, or assumes any legal liability or responsibility for any third party's use, or the results of such use, of any information, apparatus, product or process disclosed in this report, or represents that its use by such third party would not infringe privately owned rights. The views expressed in this paper are not necessarily those of the United States Government or the sponsoring agency. 


\title{
Study on Alternative Cargo Launch Options from the Lunar Surface
}

\author{
Cheryl A. Blomberg ${ }^{1}$ \\ University of Colorado Boulder, Boulder, CO, 80302 \\ Zamir A. Zulkefli ${ }^{2}$ \\ Case Western University, Cleveland, OH, 44106 \\ Spencer W. Rich ${ }^{3}$ \\ University of Washington, Seattle, WA, 98195 \\ and \\ Steven D. Howe ${ }^{4}$ \\ Center for Space Nuclear Research, Idaho Falls, ID, 83401
}

In the future, there will be a need for constant cargo launches from Earth to Mars in order to build, and then sustain, a Martian base. Currently, chemical rockets are used for space launches. These are expensive and heavy due to the amount of necessary propellant. Nuclear thermal rockets (NTRs) are the next step in rocket design. Another alternative is to create a launcher on the lunar surface that uses magnetic levitation to launch cargo to Mars in order to minimize the amount of necessary propellant per mission. This paper investigates using nuclear power for six different cargo launching alternatives, as well as the orbital mechanics involved in launching cargo to a Martian base from the moon. Each alternative is compared to the other alternative launchers, as well as compared to using an NTR instead. This comparison is done on the basis of mass that must be shipped from Earth, the amount of necessary propellant, and the number of equivalent NTR launches. Of the options, a lunar coil launcher had a ship mass that is $\mathbf{1 2 . 7 \%}$ less than the next best option and 17 NTR equivalent launches, making it the best of the presented six options.

\footnotetext{
${ }^{1}$ Graduate Research Assistant, Aerospace Engineering and Sciences, 1111 Engineering Drive, Denver, CO 80309, AIAA Student Member.

${ }^{2}$ Graduate PhD Candidate, Mechanical and Aerospace Engineering, 10900 Euclid Avenue, Cleveland, OH 44106, and AIAA Student Member.

${ }^{3}$ AIAA Student Member.

${ }^{4}$ Director of CSNR, 995 University Blvd., Idaho Falls, ID 83402, and AIAA Professional Member.
} 


\section{Introduction}

CURRENTLY, chemical rockets are the traditional propulsion method used to send cargo from Earth to other planets, but this is slow, heavy, and the rocket must carry a great deal of propellant for the entire trip, increasing the rocket mass. The fuel can range from solid to liquid to a hybrid fuel source. Even with this variety of fuel sources, the specific impulse is limited to between 250-450 s [1]. Space missions require high thrust which requires a large amount of propellant for chemical rockets.

Nuclear thermal rockets, NTR, are an improvement upon traditional chemical rockets. However, using an NTR to send cargo from Earth to Mars, the mass of the propellant for the entire mission must be carried onboard as well. The amount of propellant and structure that is required for each mission will become prohibitively expensive. This is because an incremental increase in the payload results in a significant increase in the mass of the structure and propellant required. Nuclear thermal rockets can be expendable, single burn, or multi-burn. They have an engine thrust-to-weight ratio range of 3-10 and a specific impulse between 850-1,000 s [2]. Even with these improvements over chemical rockets, creating and sustaining an outpost on Mars, which would require frequent cargo launches, would be increasingly expensive using NTRs.

An alternative to chemical rockets and NTRs is to create an electromagnetic lunar launcher to perform interplanetary transfers. This alternative would require electricity for launch instead of propellant. To launch cargo to Mars using this alternative method would require minimal on-board propellant and structural requirements. Also, an incremental increase in the payload results in an incremental increase in the power requirements, unlike the NTR and chemical rockets. In the future, the electromagnetic lunar launcher could be flexible for other interplanetary launches as well.

\section{Nuclear Power}

An important consideration in the design of the electromagnetic launcher is the design of the surface power system. Two main types of surface power systems can be utilized to provide the required power for the electromagnetic launcher; i.e. solar power and nuclear power. When deciding between the two power options, three factors must be considered. The first factor is the location requirement. For the solar power option, there is a very stringent location requirement so that enough solar energy is received by the system. In comparison, the nuclear power option's requirements are mostly related to ensuring adequate radiation shielding from the reactor core. The 
second factor under consideration is the mass of the system. For solar power system, the mass of the system increases significantly for increasing power requirements [3]. This is not the case for a nuclear power system which is typically more compact, resulting in a system mass increase proportional to the increasing power requirements. The final factor to be considered is the maintenance requirements for the different systems. For the solar power system, the system is significantly affected by the lunar environment, specifically lunar dust. This could inhibit the amount of solar energy collected by the solar panels. For the nuclear power option, there are reduced maintenance requirement when compared with the solar power system. Given the advantages of nuclear power systems when compared to solar power systems, it has been determined that nuclear power would be the most advantageous system to use to provide power to the electromagnetic launcher. Various nuclear reactors are examined and a summary of their various characteristics can be seen in Table 1.

Table 1 Summary of comparison data for nuclear reactor systems

\begin{tabular}{lccc}
\hline Nuclear System & $\begin{array}{c}\text { Power per } \\
\text { Reactor, } \mathrm{kWe}\end{array}$ & $\begin{array}{c}\text { Specific Mass, } \\
\mathrm{kg} / \mathrm{kWe}\end{array}$ & $\begin{array}{c}\text { Total System } \\
\text { Mass, tons }\end{array}$ \\
\hline SCoRe & 450 & 1.07 & 73 \\
SP-100 & 550 & 1.28 & 1112 \\
HPS & 2000 & 4.55 & 315 \\
SUSEE & 3000 & 3.00 & 202 \\
HTGR & 10000 & 0.85 & 198 \\
LMR & 20000 & 0.26 & 232 \\
\hline \hline
\end{tabular}

The main design drivers when deciding between the different nuclear surface power system options are the specific mass of the system, the total mass of the system to be shipped, and the number of reactors needed to provide the necessary power. Different nuclear systems have been compared for a power requirement of 29.3 MWe. Although the specific mass of the Sectored Compact Space Reactor (SCoRe) [4] and SP-100 [5] reactors are relatively low, the power requirement of the launcher requires multiple reactors to be utilized for surface power system which significantly increases the maintenance requirements. The Heat-Pipe Power System (HPS) [6] and SUSEE [7] meanwhile have relatively higher specific mass, which results in higher system mass for the given power requirement. The two most promising reactor systems are the High Temperature Gas Reactor (HTGR) [8] and the Low specific Mass Reactor (LMR) [9]. From comparison of the two reactors, it has been determined that the HTGR is the best system for the electromagnetic lunar launcher due to its low specific mass and low total system mass. The HTGR system provides a 10 MWe per reactor with a specific mass of $0.85 \mathrm{~kg} / \mathrm{kW}$. This means, that for a power requirement of 29.3 MWe, three reactors will be necessary, resulting in a ship total system mass of 198 metric tons. 
In addition to choosing the specific reactor to be used to provide the necessary power, some thought must also be given to the radiation shielding and heat rejection methods. To reduce the ship mass and provide the necessary radiation shielding of the nuclear core, lunar regolith has been incorporated into the radiation shield [6]. The configuration chosen for a radiation shield is the regolith-refill buried configuration. This configuration provides the necessary reactor shielding with minimal ship mass and regolith movement. For heat rejection considerations, it was determined that using a typical heat pipe radiator would require a total radiator area of 3,600 $\mathrm{m}^{2}$ resulting in a total heat rejection system mass of 47.4 metric tons. To reduce the total mass of the heat rejection system, different heat rejection methods have been compared. One alternative method is the liquid droplet radiator. The liquid droplet radiator increases the surface area of the working fluid allowing for faster heat rejection. However, a major disadvantage of the liquid droplet radiator is that the working fluid is exposed to the lack of atmosphere, which results in significant evaporation losses and fluid contamination [10]. Another alternative is to utilize a rotating bubble membrane radiator. The rotating bubble membrane radiator also increases the surface area of the working fluid, but is more compact than the liquid droplet radiator [11]. Furthermore, the working fluid for rotating bubble membrane radiator is contained, resulting in lower evaporation losses and less contamination. Thus, the rotating bubble membrane radiator was chosen as the heat rejection method for the electromagnetic launcher.

Because of its superior efficiency and low total mass, a High Temperature Gas Reactor has been chosen. Using the HTGR, only three reactors would be necessary in order to provide the proper amount of power. The HTGR needs shielding, which would be provided using lunar regolith, as well as a method for heat rejection. The best heat rejection method for this situation is the rotating bubble membrane radiator because it increases the surface area of the working fluid within a closed system.

\section{Interplanetary Lunar Launcher}

The interplanetary lunar launcher has many different options from magnetic track to levitating coils. For this reason, the options are split into six different categories. The first uses current (2012) technology and the subsequent options become more theoretical. The interplanetary lunar launcher will have a payload of 100 tons, with a radius of $10 \mathrm{~m}$ and a length of $28 \mathrm{~m}$. The launcher system length, based on the parameters assumed for the study, is about $88 \mathrm{~km}$. This payload will be launched from Earth to low Earth orbit (LEO) using an NTR and then an NTR will be used to transport the cargo to low lunar orbit (LLO). Once on the moon, the launch window for the 
launcher for Mars is variable but the launchers are designed to launch once a day. Due to the possible fragility of the cargo, the maximum g-force that the cargo can endure has been limited to $15 \mathrm{G}$ 's. The $\Delta \mathrm{V}$ to escape from both Earth and the moon's gravity wells is $5 \mathrm{~m} / \mathrm{s}$.

\section{A. Option 1: Maglev}

Option one uses all current technology in order to make a magnetic levitating train (maglev) to launch a 100 ton payload from the lunar surface to Mars. The lunar maglev design is based on the German Transrapid, a high-speed monorail train that uses magnetic levitation.

The levitation system used is electromagnetic suspension (EMS). The interaction between the magnets and coils in the track provide a constant levitation between one and ten centimeters [12]. The propulsion source is from long primary type stator coils. The smaller air gap associated with using a linear motor means that the efficiency approaches $80 \%$ [10]. Magnetic repulsive forces are used as the guidance system which keeps the sled on the track.

For the lunar maglev track, the support structure and dead-man anchors are made from carbon steel, and the track and sled have the option of being made from carbon steel or aluminum. The superconducting magnets are magnesium bromide because they are less brittle and can handle the extreme temperature swings that occur on the lunar surface [12]. All the components in option one are constructed on Earth and then shipped to the lunar surface for final construction.

\section{B. Option 2: In-Situ Maglev}

Option two is based on the same current technology as option one but will be constructed from as much in-situ material as possible. The mass is the limiting factor for this project because it is expensive to ship cargo from Earth to the moon. By using lunar resources to construct as many of the option two components as possible, the mass, and therefore the cost, can be minimized. It is assumed that once the extraction and mining equipment for obtaining the in-situ materials has arrived on the moon, using them is effectively cost-free. The equipment that must be sent up includes dump trucks, cranes, electric shovels, and the equipment for a refining/LOX plant [15]. Certain components of the launcher must still be constructed and shipped from Earth, including the superconducting magnets, the reactors, and parts of the capacitors. 
In option two, iron or sulfur concrete makes up the structure. The construction material for the structure depends on the location of the track on the lunar surface and the amount of structure that is required in that location. The sulfur concrete is created using $20 \%$ sulfur extracted from the moon and $80 \%$ regolith as aggregate [11]. The tracks are constructed from in-situ iron. The capacitors, for energy storage, are barium titanium dioxide. These are made from titanium dioxide that can be found on the moon, resulting in less shipping mass.

\section{Option 3: Linear Synchronous Motors}

Linear synchronous motors (LSM) are traditionally used in maglev systems such as option one and two. They use opposing magnetic poles in the center of the sled for levitation. Behind the sled, the poles are the same resulting in a pushing force; in front of the sled the poles are opposite resulting in a pulling force on the sled. Due to the nature of the atmosphere and the reduced gravitational field on the moon, LSM can be used individually with reduced structural components as compared to Earth-based maglev systems.

The LSM used in option three are double sided, planar, air-cored, and slotless with only one internal armature. By using air-cored LSM, the lunar atmosphere can act as a cooler, resulting in a reduced launching mass from Earth as compared to iron-cored LSM. Slotless LSM result in a higher efficiency within the higher speed range, lowers the cost of the winding, lowers the acoustic noise, and lowers the thrust pulsations making the LSM more stable at higher speeds [13]. For a LSM, there are two options for a damper: aluminum cover or solid steel pole shoes. A damper is used to mitigate the effects of small changes in the speed or magnetism within the LSM. It dampens the oscillations allowing the motor to return to synchronous operation, as well as reducing the backward traveling field [13]. Because aluminum can be extracted from the moon, an aluminum cover will be used as the damper, even though using an aluminum cover increases the mass of the system more than the steel pole shoes would.

\section{Option 4: Conductive Glass Road}

Option four uses in-situ materials in order to create the entire structure and roadway for a sled and cargo to travel down in order to reduce the shipping mass. The roadway is created by sintering regolith into glass. Adding in-situ aluminum to the regolith as it is being sintered and inducing a magnetic charge in it would allow the track to be conductive. Because the structure is now a flat glass road, all the levitation and propulsion mechanisms are incorporated into the sled. Lasers beam power to the sled from the surface reactors. Including the superconducting magnets, cargo, power beaming receiver, and heat radiators, the mass of the sled would be about 920 tons. 
Using power beaming, the entire amount of necessary power to launch the cargo must be sent to the sled simultaneously. In regards to the lasers, the maximum efficiency for light conversion is $50 \%$ and due to laser diffraction, there is another large efficiency drop-off of $20 \%$ in $12 \mathrm{~km} \mathrm{[14].} \mathrm{Due} \mathrm{to} \mathrm{these} \mathrm{efficiencies,} \mathrm{the} \mathrm{power}$ needed increases to $268 \mathrm{GW}$ which would results in needing 10.72 million lasers. Also, the entire track must be completely flat so the laser has direct line of sight to the sled for the entire length of the track [16]. This results in extra structural components for the glass road. Due to the number of lasers needed and the excessive amount of power that must be produced and beamed simultaneously to the sled, this option is deemed unfeasible at this time without groundbreaking technology advancement.

\section{E. Option 5: Coil Launcher}

Another option for the lunar launcher is to use electromagnetic coils to accelerate the payload from the lunar surface into the orbit of Mars. The circular coils are arranged perpendicularly along the axial length of the track and a specified current in applied to each coil. Due to Ampere's Law, the current flowing in the coils will induce a magnetic field. This magnetic field will in turn induce a net force on the payload placed in the center of the coils. This electromagnetic force is sufficient to levitate and center the payload. By controlling the current in each coil along the axial direction of the track, a net axial force can be produced which results in a linear acceleration of the payload along the axial direction. An attractive feature of the electromagnetic coil launcher design is the ability of the system to center the payload, providing the necessary centripetal force to keep the payload along the track as it is being accelerated.

Previous studies on utilizing electromagnetic coil launchers have been carried out. In 1977, a summer study at NASA Ames Research investigated a conceptual design analysis of electromagnetic coil launcher on the lunar surface [21]. Additionally, recent research utilizing electromagnetic coils as coil-guns have also been carried out at Sandia National Laboratory [22]. The research has concluded that electromagnetic coils are a possible alternative method to accelerate payloads to the required velocity without the use of rockets.

The design of the coil lunar launcher is primarily based on the work carried out by the 1977 summer study at NASA Ames Research Center. However, to reduce the shipped mass of the design, modifications in the design are carried out to use as much in-situ resources as possible. For the modified design, the coils, structure, and capacitors are made with in-situ resources. The resources include aluminum, regolith derivatives, and titanium dioxide. 


\section{F. Option 6: Orbital Accelerator}

One practical difficulty that was encountered in the course of studying a lunar electromagnetic launcher was the scale of the project, $88 \mathrm{~km}$ as previously stated. In orbit, the length of the system becomes immaterial as the accelerating force is imparted over a large distance without the use of a coherent structure. A number of electromagnetic accelerator modules may be placed in a polar orbit in order to accelerate a payload over the course of $1,000 \mathrm{~km}$ or more. Each unit stores a small portion of the total energy that must be imparted onto the payload. Preliminary estimates suggest that the power requirements for this system are easily met with conventional photovoltaic arrays. If a solar concentrator is used to illuminate an actively cooled solar array, mass savings are achieved [20]. The acceleration of the payload imparts a uniform momentum onto each module; this results in the orbital velocity of each module being slightly perturbed.

Instead of expending propellant to reposition each module back into the launch configuration, the accelerator coil in each module may be energized. The resultant magnetic field will interact with the Earth's magnetosphere, imparting a force that will result in each module being repositioned into the proper orbit. Electrodynamic tethers may also be extended to provide the repositioning force as well as handling routine station-keeping and attitude control functions [19]. Each module may be repositioned within Earth's magnetosphere in a manner of hours. The energy storage system on board for energizing the coils during a launch may be recharged in similar duration.

The circular polar orbit will be parallel to the ecliptic twice during each two hour orbital period. When the end of the accelerator system is tangent with the ecliptic, a payload may be launched through the system. The design of the system inherently allows the change in velocity that is imparted onto the payload to be continuously variable, allowing the orbital accelerator to have a suitable launch window.

\section{Analysis}

The options are compared three different ways: total shipped mass, total propellant mass, and the number of equivalent NTR launches. The total shipped mass is the mass of any components or materials that must be shipped from Earth in order to construct the interplanetary lunar launcher. The total propellant mass takes into account both launching the total shipped mass from Earth to the lunar surface, as well as the propellant needed to put the launched

cargo into the orbit of Mars. The number of equivalent NTR launches takes into account how many launches of an NTR are equal to one launch of each of the various interplanetary lunar launchers. 
The conductive glass road is not compared to the other options due to the unfeasibility of the option at this time. As power beaming technology continues to advance, this option may become feasible and then a comparison to the other options could be completed.

The orbital accelerator is a theoretical design for which the technology does not yet exist. Due to the nature of this option, the mass that must be shipped from Earth could not be calculated to the detail of the other options. Also, because the orbital accelerator is in medium Earth orbit instead of being on the lunar surface, the launchers are not directly comparable.

Table 2 Summary of comparison data

\begin{tabular}{lccc}
\hline \hline Option & $\begin{array}{c}\text { Shipped Mass, } \\
\text { tons }\end{array}$ & $\begin{array}{c}\text { Total Propellant } \\
\text { Mass, tons }\end{array}$ & $\begin{array}{c}\text { Equivalent } \\
\text { NTR } \\
\text { Launches }\end{array}$ \\
\hline Maglev & 44797 & 219751 & 1112 \\
In-Situ Maglev & 961 & 4945 & 25 \\
LSM & 710 & 3715 & 19 \\
Coil Launcher & 620 & 3276 & 17 \\
\hline \hline
\end{tabular}

For each of the lunar-based options, the mass for the nuclear surface reactors to provide the necessary power is the limiting factor. The HTGR produces $10 \mathrm{MW}$ per reactor with a mass of 49.4 tons each [18]. The launchers are designed to be launched daily in order to take advantage of every launch window. The power storage is not reducing the mass as much as it could if the launch windows were more consistently spaced.

Table 3 Comparison of reactor mass versus total shipped mass

\begin{tabular}{lccc}
\hline \hline Option & $\begin{array}{c}\text { Shipped Mass, } \\
\text { tons }\end{array}$ & $\begin{array}{c}\text { Mass of } \\
\text { Reactors, tons }\end{array}$ & $\begin{array}{c}\text { Reactor Mass } \\
\text { Percentage, \% }\end{array}$ \\
\hline Maglev & 44797 & 98 & 0.2 \\
In-Situ Maglev & 961 & 98 & 10.2 \\
LSM & 710 & 148 & 20.8 \\
Coil Launcher & 620 & 148 & 23.9 \\
\hline \hline
\end{tabular}

The percentage of the reactor mass of the total shipped mass is shown in Table 3. Initially, the reactor mass was the limiting factor for shipping components to the lunar surface. By using the HTGR and its increased power-tomass ratio of $0.20 \mathrm{MW} /$ ton, the percentage of the shipping mass that is made up by the reactors is decreased.

The coil launcher is the best option according to all three comparisons. The amount of mass that must be shipped is the lowest which results in less propellant being used. Because less propellant is used, there are a lower number of equivalent NTR launches. This means that each launch of the coil launcher sends 100 tons of cargo to 
Mars from the lunar surface. For the same amount of propellant, 1,700 tons of cargo could be sent to Mars directly from Earth using NTRs. According to these comparisons, NTRs are better to use as compared to the various launcher options.

\section{Orbital Mechanics}

Determining the usefulness of a lunar launcher hinges on whether the orbital mechanics allow for $\Delta \mathrm{V}$ savings through an impulsive launch. Using AGI's Satellite Tool Kit, lunar launches were simulated for a three year period to characterize the launch dates and patterns.

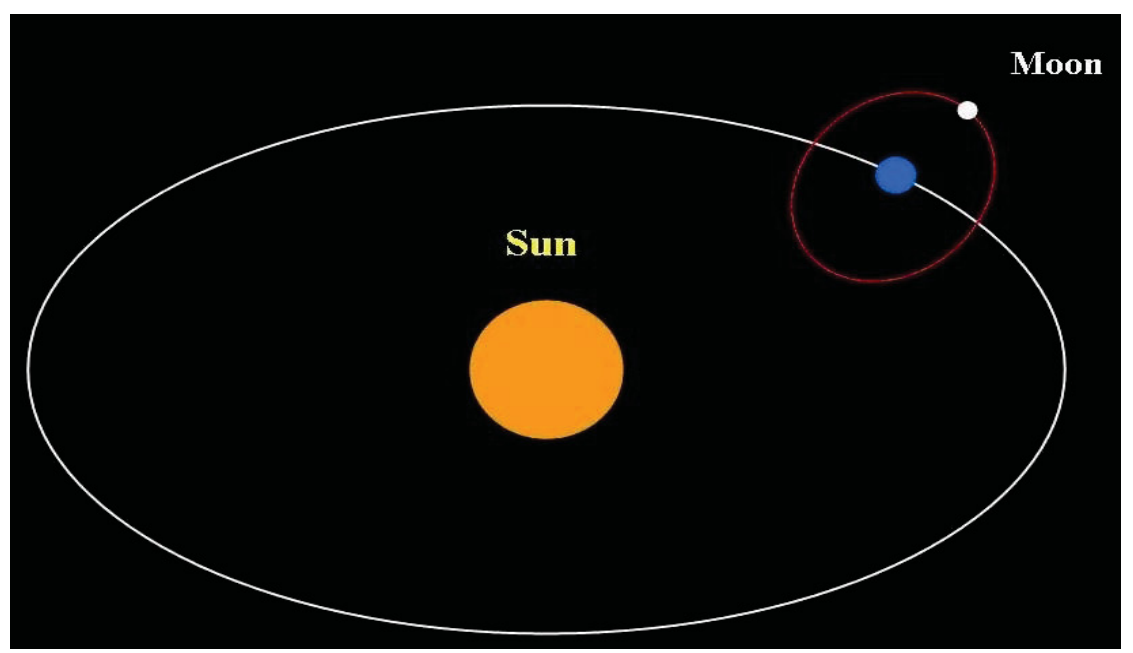

Figure 1 The orbit of the moon around the Earth with respect to the Sun

Shown above in Figure 1, the Earth and Moon orbit the sun in a counter-clockwise direction. Due to this orbital route and the tidally locked Moon, the launcher must be placed on the far side of the moon away from the Earth in order to take full advantage of the Earth-Moon system. Building the launcher on the Earth-facing side of the Moon or light side would greatly restrict launch windows and would be fighting against the $1 \mathrm{~km} / \mathrm{s}$ rotation of the Moon. According to initial estimates, a local minimum energy launch opportunity would occur every 26 months with an absolute minimum every 16 years. This was determined following the synodic period of the Earth-Mars system. 


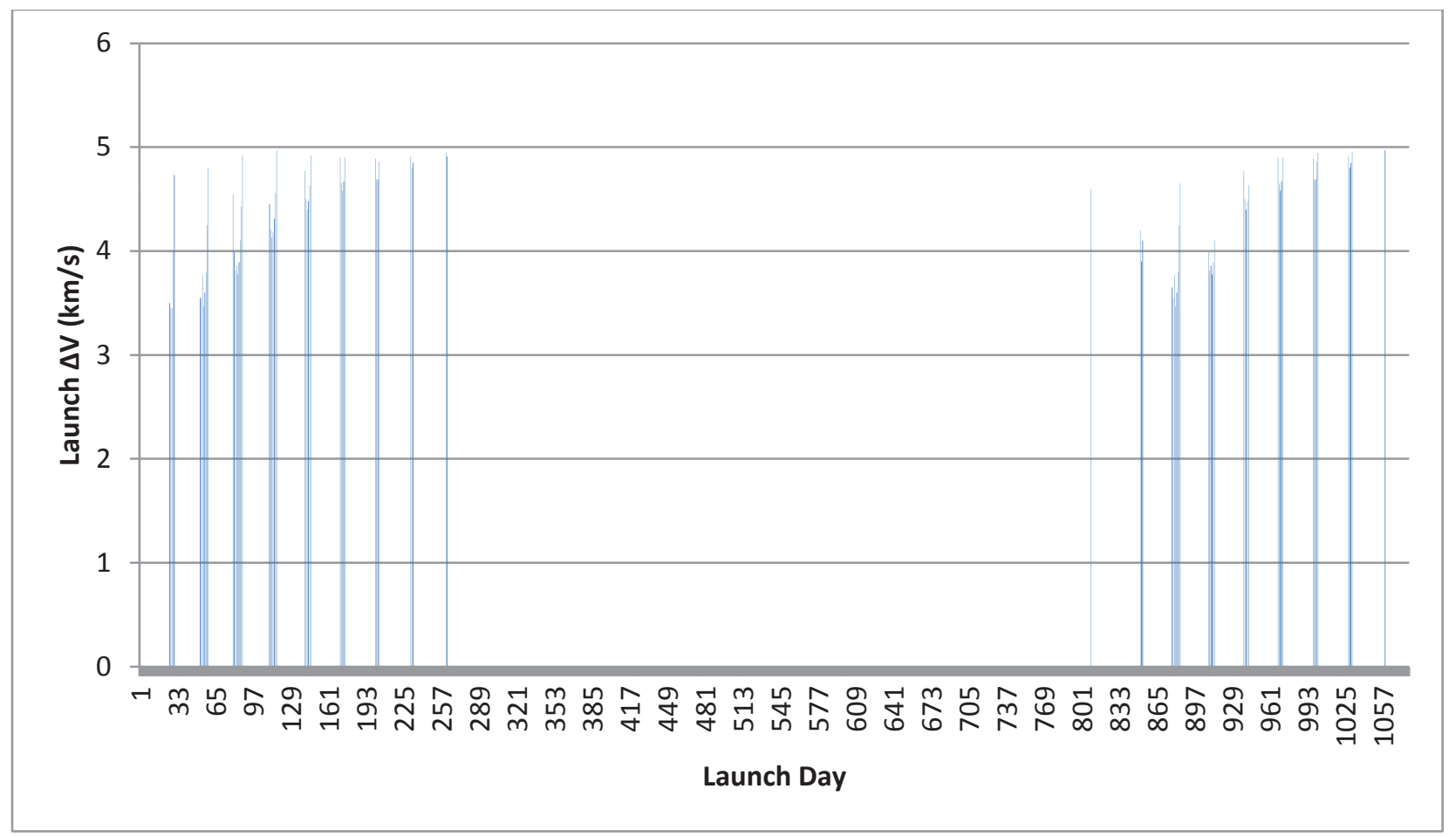

Figure 2 The possible launch dates over a 26 month period using less than $5 \mathrm{~km} / \mathrm{s} \Delta \mathrm{V}$

The initial launch feasibility study was conducted by iterating over each day in a 1,067 day period. A launch is considered feasible if the launched payload could be in phase with Mars on a launch $\Delta \mathrm{V}$ of less than $5 \mathrm{~km} / \mathrm{s}$. The 5 $\mathrm{km} / \mathrm{s}$ limitation is a trade-off between increasing the number of launch dates and decreasing the amount of mass and power necessary to install and use on the lunar surface. These results represent only the launch to Martian orbit, not a Mars capture orbit. Figure 2 can be difficult to interpret due to the amount of data collected, but there are approximately 30 launch dates per year over the three year period. However, there is a period of about 450 days of inactivity where the orbits of the Earth-Moon system and Mars are completely out of phase. Using this limited launcher, there are numerous possible launch dates, but with a more powerful launcher, the number would increase. 


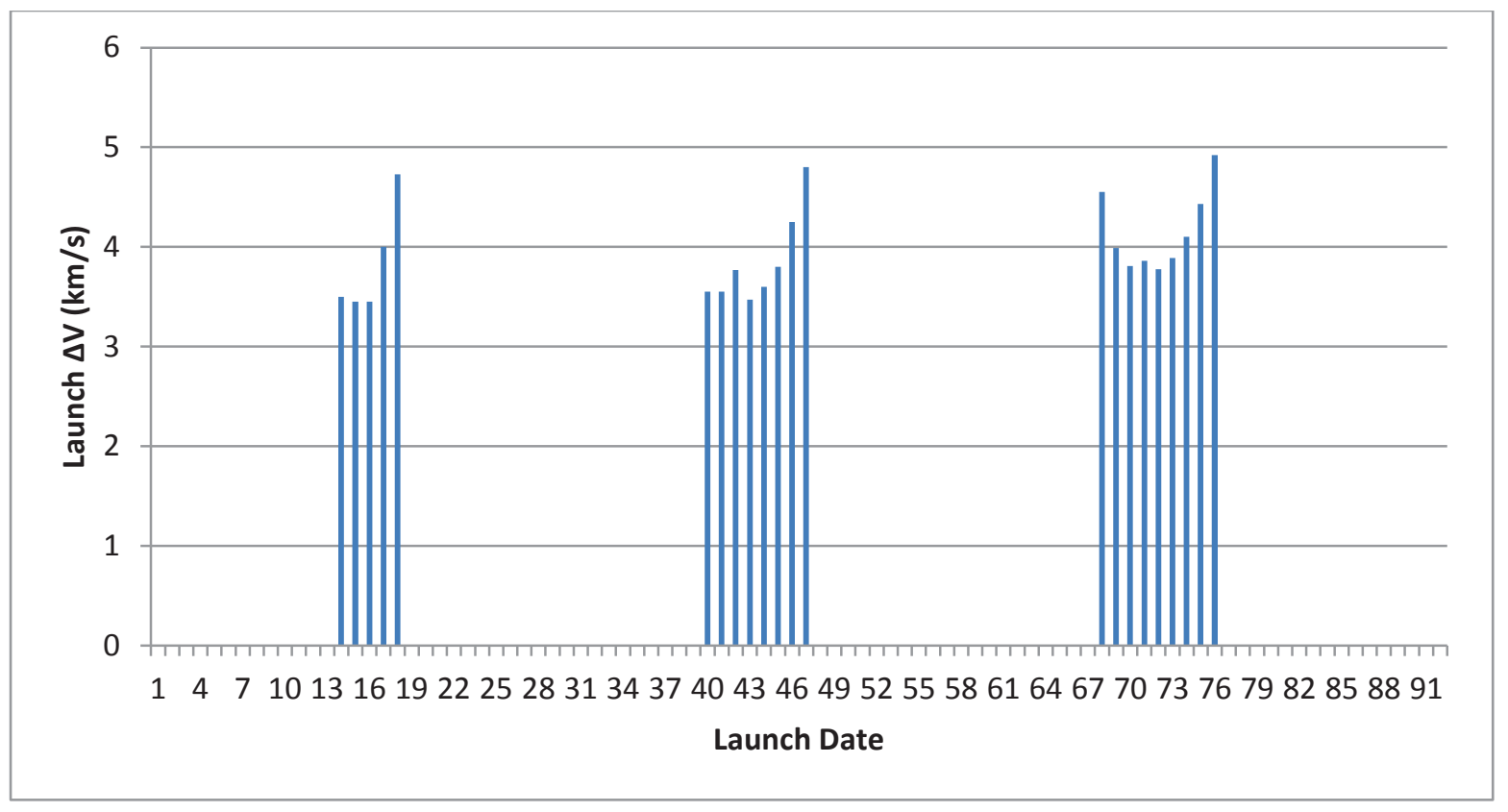

Figure 3 Expansion of the $2^{\text {nd }}$ through $4^{\text {th }}$ months to show detailed, month-by-month characteristics

The original plan was to launch once per month in order to charge up the system, resulting in less nuclear reactors to provide the necessary power. After determining the future launch windows, this plan was deemed unrealistic. Because the launch windows occur in a quick succession of days, daily launching capability must be available when the windows are open to maximize the effectiveness of a lunar launcher. The duration in which the launcher is unable to launch to Mars is due to the lunar orbit period. To highlight how an extended lunar launcher could affect launch capabilities, the same 3-month period is shown with a limit of $12 \mathrm{~km} / \mathrm{s}$ instead of $5 \mathrm{~km} / \mathrm{sin}$ Figure 4. This increase in capability nearly doubles the number of launches in the period, from 22 total and 7.3 average per month to 40 total and 13.3 average. These high energy launch windows have some major drawbacks. The $\Delta \mathrm{V}$ required to fix the orbits into a Mars capture orbit increases from an average of $5.8 \mathrm{~km} / \mathrm{s}$ for the launches under $5 \mathrm{~km} / \mathrm{s}$ to about $9.3 \mathrm{~km} / \mathrm{s}$ for the launches up to $12 \mathrm{~km} / \mathrm{s}$. The phasing orbit can take an extraordinarily long period of time compared to the slower launches as well. Since the payload is launching well ahead of Mars, the payload enters a much larger orbit and waits for Mars to catch up in a more eccentric orbit, thus the time of flight can be between 1.5 and 3 years. 


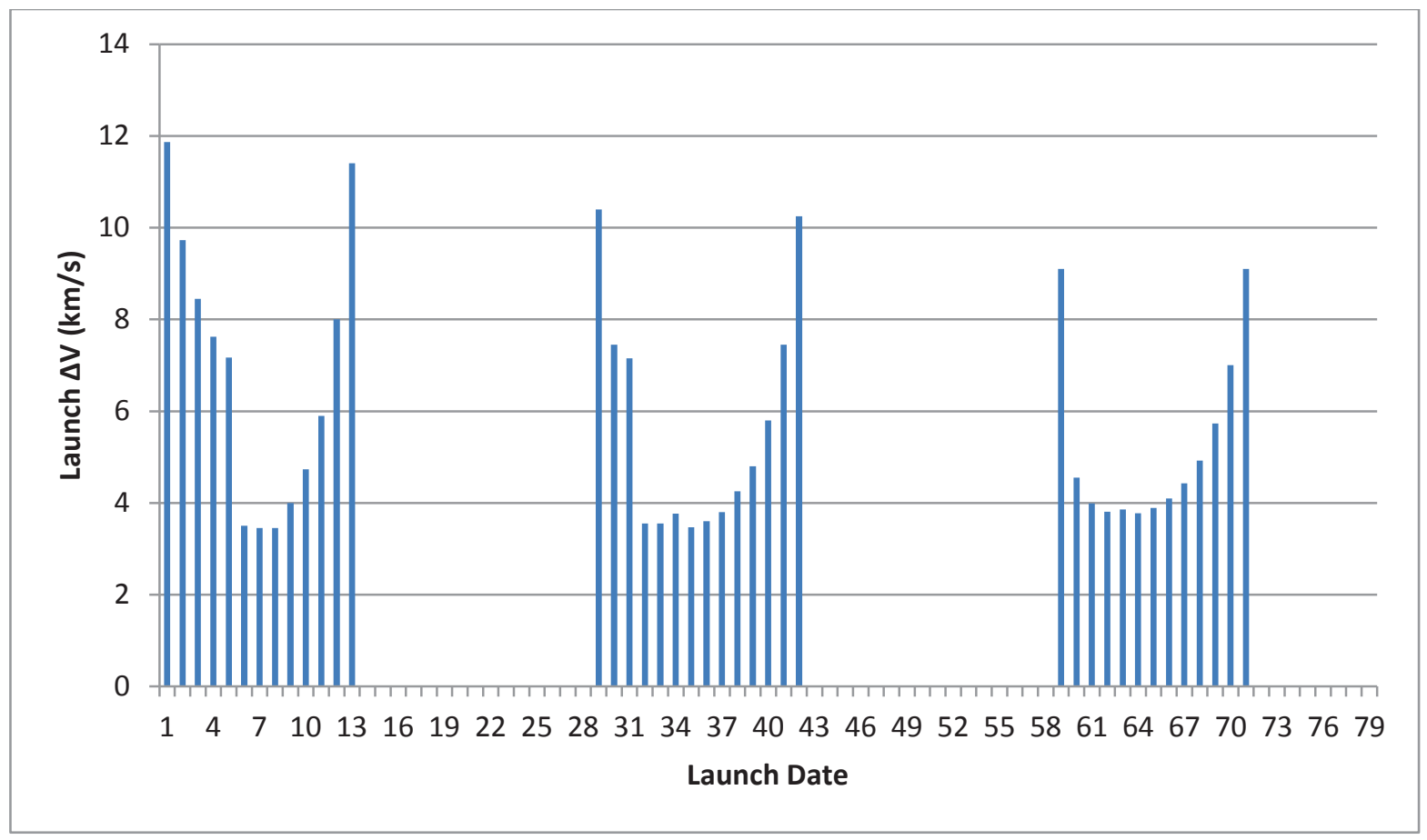

Figure 4 Effects of extended lunar launcher on launch availability

A simple launch with no correction will not lead to a Mars capture orbit without a midcourse correction. Midcourse corrections for three selected months have been generated and the results are shown below in Figure 5

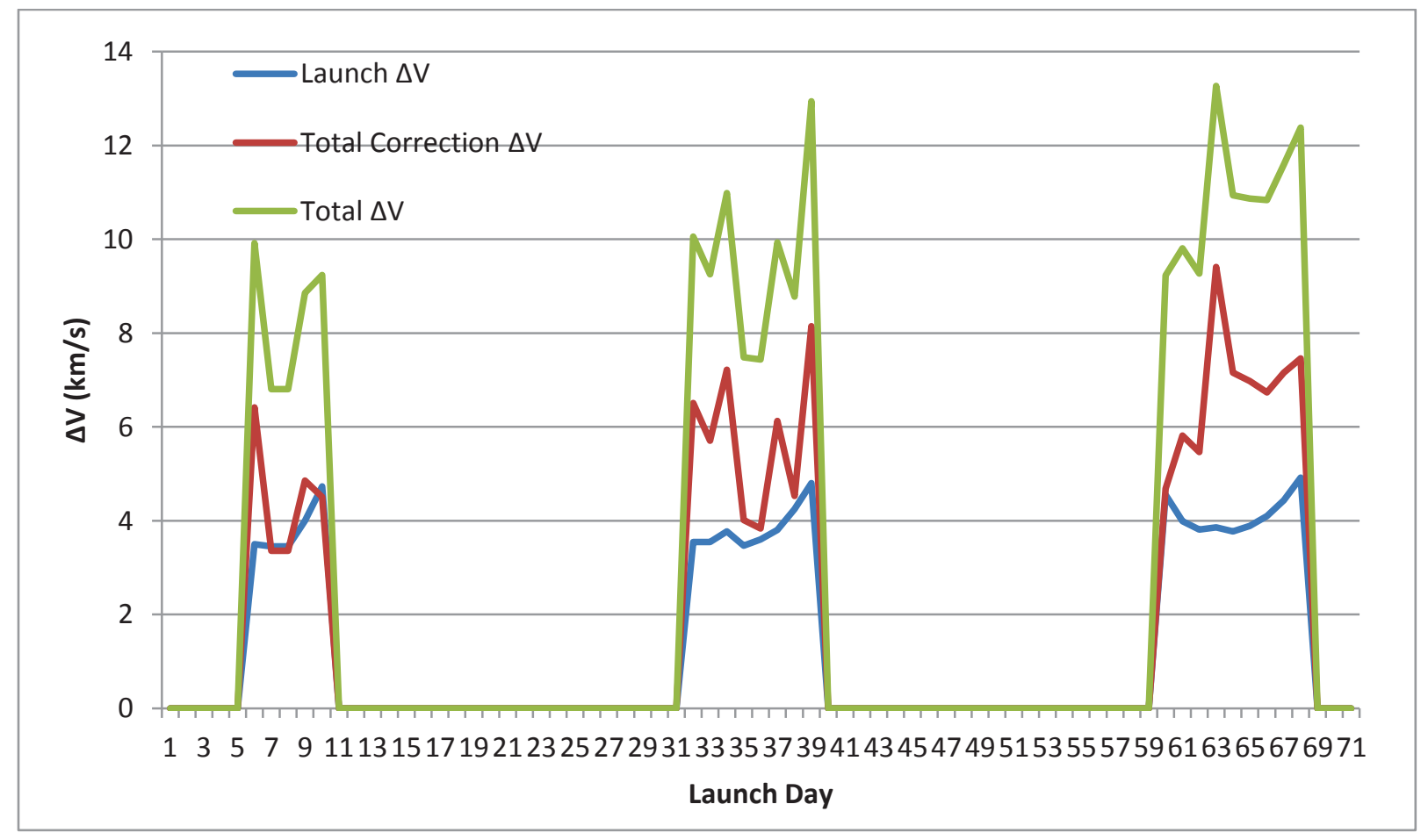

Figure 5 Total necessary delta $\mathrm{V}$ based on launch date 
The red line represents the $\Delta \mathrm{V}$ capability the payload craft will have to possess beyond launch. In all cases, it is at least as much as the launch $\Delta \mathrm{V}$ if not more. However, these are non-optimized cases. Optimization can lead to more accurate and lower $\Delta \mathrm{V}$ values. The average correction for launches under $5 \mathrm{~km} / \mathrm{s}$ is $5.8 \mathrm{~km} / \mathrm{s}$ of which $3.6 \mathrm{~km} / \mathrm{s}$ being dedicated to the transfer orbit and $2.2 \mathrm{~km} / \mathrm{s}$ used for the actual capture.

Using the Mars Mission Trajectory Optimization Program (MMTOP), a Matlab script developed at the Center for Space Nuclear Research, the average optimized $\Delta \mathrm{V}$ for a LEO to Mars trajectory is shown in Table 4 . The propellantless $\Delta \mathrm{V}$ is the average launch requirement. The average $\Delta \mathrm{V}$ savings per launch can be used to calculate mass fractions and drives the entire gear ratio. Further optimization of the launches and captures would drive this number higher but conservative estimates of the average savings is about $3 \mathrm{~km} / \mathrm{s}$.

Table 4 Optimized delta V for LEO to Mars trajectories

\begin{tabular}{lccc}
\hline \hline Option & $\begin{array}{c}\text { Average } \\
\text { Propellant } \\
\Delta \mathrm{V}, \mathrm{km} / \mathrm{s}\end{array}$ & $\begin{array}{c}\text { Average } \\
\text { Propellantless } \\
\Delta \mathrm{V}, \mathrm{km} / \mathrm{s}\end{array}$ & $\begin{array}{c}\text { Average Savings } \\
\text { per Launch, km/s }\end{array}$ \\
\hline NTR & 8.75 & 0 & --- \\
Lunar Launcher & 5.81 & 4.35 & 2.94 \\
\hline \hline
\end{tabular}

The orbits involved with a lunar launcher provide brief periods of very active launch windows contrasted with long durations of inactivity, so increasing the power availability would greatly aid in providing more launches. Although higher $\Delta \mathrm{V}$ launches enable a greater volume of launches, the drawbacks of a much higher transit time and fuel requirements reduce the effectiveness of the launch system. The optimum between flight time, $\Delta \mathrm{V}$ for correction, power consumption for charging, and launch windows appears to be at a launcher capable of $5 \mathrm{~km} / \mathrm{s}$ launches.

Despite the work presented here, there is more work to be done in the future to completely understand the orbital mechanics of a lunar launcher. The mid-course correction $\Delta \mathrm{V}$ 's are high estimates since the trajectories were nonoptimized. To get a better understanding of the savings of the launcher, optimized trajectories would be necessary. Comparing some of the high energy launch dates from the launcher with NTR LEO launches would also determine if there are $\Delta \mathrm{V}$ savings to be found. Determining an efficient lunar delivery schedule may also reduce the cost of delivering the lunar launcher parts to the moon's surface. Extending the launch window study would be useful to analyze far reaching patterns. 


\section{Conclusions}

The coil launcher is the best alternative to chemical and nuclear thermal rockets for launching cargo to Mars. By using in-situ resources, the shipped mass is 620 tons which reduces the necessary propellant to 3,276 tons. The equivalent number of NTR launches is 17, which is 2 less than any other lunar-based option. Also, due to the modular nature of the coil launcher, adding more coils in the future to either launch people from the moon to Mars at slower speeds or launch cargo to farther planets are higher speeds. By launching to multiple planets, the number of launch windows for the coil launcher increases.

The other options, specifically the conductive glass road and the orbital accelerator, may become more competitive in the future with better technology. With a continuing increase in the power beaming technology, the efficiency will increase, thereby reducing the number of lasers necessary. This will make option four, the conductive glass road, more feasible and worth further investigation. The orbital accelerator can become more competitive when the technology to complete this project exists. The capability for flexible launch windows is a large advantage for option six, the orbital accelerator, over the other stationary, lunar-based options.

With all six of the options, the NTRs outperform any of the alternative cargo launcher designs. Unless large developments are made in reducing the shipped mass of the launchers, the lunar launchers cannot compete. Also, an increase in the launch windows would make the lunar launcher options more reasonable. One way to increase the launch windows would to enable the interplanetary lunar launcher to adjust its angle on the ecliptic plane. Due to these issues, research should continue on improving NTRs.

\section{Acknowledgments}

The authors would like to thank Charles Fisk, Alex Perez, and Theodore Hale for being additional members of the Interplanetary Lunar Launcher team and for their work on this project. The Interplanetary Lunar Launcher team would like to thank Dr. Steven Howe for his mentorship and guidance throughout the project. The team also would like to thank the Center for Space Nuclear Research (CSNR) for funding our research and bringing our team together. Finally, we thank the Center for Advanced Energy Studies (CASE) for allowing us to use their building as well as Idaho National Labs (INL) for allowing us access to their research resources and personnel. 


\section{References}

[1] Hickman, J.M. and Bloomfield, H.S., "Comparison of solar photovoltaic and nuclear reactor power systems for a humantended lunar observatory."; $24^{\text {th }}$ Intersociety Energy Conversion Engineering Conference (IECEC-89) Vol. 1, IEEE, New York, NY pp. 1-5, 1989.

[2] Hatton, S.A. and El-Genk, S.; "Sectored Compact Space Reactor (SCoRe) concepts with a supplementary lunar regolith reflector"; Progress in Nuclear Technology 51 (2009) 93-108, 2009.

[3] NASA, Lewis Research Center; "Lunar Electric Power Systems Utilizing the SP-100 Reactor Coupled to Dynamic Conversion Systems"; NASA Contractor Report CR-191023, March 1993.

[4] Poston, D.I., Kapernick, R.J., Guffee, R.M., Reid, R.S., Lipinski, R.J., Wright, S.A., Talandis, R.A; “Design of a HeatpipeCooled Mars-Surface Fission Reactor"; Space Technology and Applications International Forum-STAIF 2002.

[5] Maise, G. , Powell, J. and Paniagua, J.; "SUSEE: A Compact, Lightweight Space Nuclear Power System Using Present Water Reactor Technology"; Space Technology and Applications International Forum - STAIF 2006, pp 308-318, 2006.

[6] Juhasz, A.J. , El-Genk, M.S. and Harper, W.B.; “Closed Brayton Cycle Power System with a High Temperature Pellet Bed Reactor Heat Source for NEP Applications”; NASA TM-105933, Jan. 1993.

[7] Deason, W., Ferrulli, R. Gupta, M., Hoifeldt, N., Reneau, J. and Sudderth, L.; “ Trade Study of a 20 Megawatt Electric Low Specific Mass Nuclear Power System for Space Propulsion”; Proceedings of Nuclear and Emerging Technologies for Space, Feb 7-10, 2011.

[8] White, A.K.; “Liquid Droplet Radiator Development Status”; NASA Technical Memorandum 89852, 1987.

[9] Webb, B.J. and Antoniak, Z.I.; "Rotating Bubble Membrane Radiator for Space Applications"; Proceedings of the 21 ${ }^{\text {st }}$ Intersociety Energy Conversion Engineering Conference: IECEC '86, Vol. 3, pp 1881-1885, 1986.Lee, J., \& Kim, K. (2006). Review of Maglev Train Technologies. IEEE Transactions on Magnetics, 42(7), 1917-1925.

[10] Toutanji, H., \& Grugel, R. (2008). Sulfur 'Concrete' for Lunar Aplications-Sublimation Concerns. Advances in Space Research, 41(1), 103-112.

[11] Vinod, K., Abhilash Kumar, R., \& Syamaprasad, U. (2007). Prospects of MgB2 Superconductors of Magnet Application. Superconductor Science and Technology, 20(1), R1-R13.

[12] Gieras, J. F., Piech, Z. J., \& Tomczuk, B. (2012). Linear Synchornous Motors: Transportation and Automation Systems (2 ed.). New York: CRC Press.

[13] Sprangle, P., Ting, A., Penano, J., Fischer, R., \& Hafizi, B. (2008). High-Power Fiber Lasers for Directed-Energy Applications. Naval Research Lab.

[14] University of Washington Space Systems Design Team. (2012). MAVERIC: Mission for the Acquisition of Valuable Extraterrestial Resources for Industrial Commercialization. RASC-AL Forum. 
[15] Nugent, T. J., \& Kar, J. T. (2011). Laser Power Beaming for Defense and Security Appcliations. Society of Photo-Optical Insturmentation Engineers. LaserMotive.

[16] Borowski, S. K., Corban, R. R., McGuire, M. L., \& Beke, E. G. (1993). Nuclear Thermal Rocket/Vehicle Design Options for Future NASA Missions to the Moon and Mars. Cleveland: NASA.

[17] Sutton, G. P., \& Biblarz, O. (2011). Rocket Propulsion Elements (8 ed.). New York: John Wiley \& Sons

[18] Juhasz, A. J. (2006). Multi-Megawatt Gas Turbine Power Systems for Lunar Colonies. 4th International Energy Conversion Engineering Conference and Exhibit. American Insitute of Aeronautics and Astronautics.

[19] Cosmo, M. L., \& Lorenzini, E. C. (1997). Tethers in Space Handbook. In Smithsonian Astrophysical Observatory.

[20] Kurtz, S. (2012). Opportunities and Challenges for Development of a Mature COncentrating Photovoltaic Power Industry. Golden: National Renewable Energy Laboratory.

[21] (1979). Space Resources and Space Settlements. Washington D.C.: NASA.

[22] Sandia National Labs. (2001). Results of a Study for a Long Range Coilgun Naval Bombardment System. Albuguerque: Sandian National Labs. 